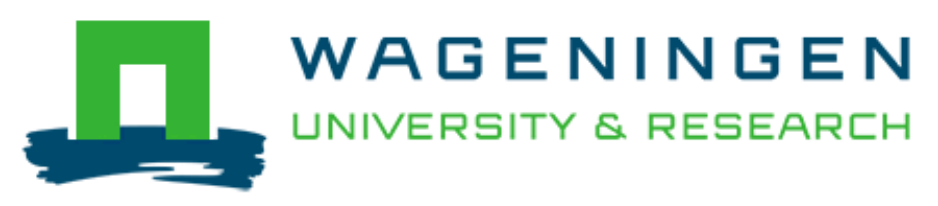

GrassVESS: a modification of the visual evaluation of soil structure method for grasslands

Emmet-Booth, J. P., Bondi, G., Fenton, O., Forristal, P. D., Jeuken, E., Creamer, R. E., \& Holden, N. M.

This article is made publically available in the institutional repository of Wageningen University and Research, under article 25fa of the Dutch Copyright Act, also known as the Amendment Taverne.

Article $25 f a$ states that the author of a short scientific work funded either wholly or partially by Dutch public funds is entitled to make that work publicly available for no consideration following a reasonable period of time after the work was first published, provided that clear reference is made to the source of the first publication of the work.

For questions regarding the public availability of this article, please contact openscience.library@wur.nl.

Please cite this publication as follows:

Emmet-Booth, J. P., Bondi, G., Fenton, O., Forristal, P. D., Jeuken, E., Creamer, R. E., \& Holden, N. M. (2018). GrassVESS: a modification of the visual evaluation of soil structure method for grasslands. Soil Use and Management, 34(1), 37-47. https://doi.org/10.1111/sum.12396 


\title{
GrassVESS: a modification of the visual evaluation of soil structure method for grasslands
}

\author{
J. P. Emmet-Booth ${ }^{1}$ iD, G. Bondi ${ }^{2}$, O. Fenton ${ }^{2}$, P. D. Forristal ${ }^{3}$, E. Jeuken ${ }^{4}$, R. E. Creamer $^{2,5}$ \& \\ N. M. HoLdeN ${ }^{1}$ \\ ${ }^{1}$ School of Biosystems \& Food Engineering, University College Dublin, Belfield, Dublin 4, Ireland, ${ }^{2}$ Teagasc Environment Research \\ Centre, Johnstown Castle, Co. Wexford, Ireland, ${ }^{3}$ Crop Science Department, Teagasc Oak Park, Co. Carlow, Ireland, ${ }^{4}$ Centre for \\ Environment Research Innovation and Sustainability, IT Sligo, Co. Sligo, Ireland and ${ }^{5}$ Department of Environmental Science, \\ Wageningen University, PO Box 47,6700 AA, Wageningen, The Netherlands
}

\begin{abstract}
Visual evaluation of soil structure (VESS) is used for assessing arable management impact on soil quality. When used on pastures, operators have identified limitations because VESS does not consider a surface root-mat typical of managed grassland. The structure of the root-mat may be indicative of nutrient use efficiency, pollution potential and subsurface compaction. The objectives of this research were to develop GrassVESS for grassland soil management, to compare it with VESS and quantitative physical indicators and to assess its utility for soil management. GrassVESS maintained the methodological strengths of VESS, but uses a flow chart, grassland images and a new root-mat score. A focus group found GrassVESS to be quicker, dealt better with technical information and made root-mat evaluation easier. The range of structural quality scores assigned by the focus group for a site was less for GrassVESS than VESS, suggesting the procedure is more reproducible, thus suitable for use by a range of stakeholders. GrassVESS was also deployed at 30 grassland sites across Ireland. Results indicated that GrassVESS generated the same overall diagnoses as VESS, but the GrassVESS root-mat structural quality score was better related to bulk density, total porosity at 5$10 \mathrm{~cm}$ and a visual estimation of damaged sward area. It was concluded that GrassVESS has improved the VESS method for the specific assessment of grassland soil structural quality and could be used in real-time farm management decision support.
\end{abstract}

Keywords: Sustainable soil management, visual soil evaluation, grassland soil quality, root-mat evaluation, soil structure

\section{Introduction}

Visual soil evaluation (VSE) techniques are valuable for soil quality assessment (Mueller et al., 2013; Askari et al., 2015) and sustainable soil management (Shepherd, 2009; Ball et al., 2017). Numerous procedures have been critically reviewed (Emmet-Booth et al., 2016) involving the visual and tactile assessment of soil structure (Ball et al., 2013). The visual evaluation of soil structure (VESS) method (Ball et al., 2007; Guimarães et al., 2011) has gained popularity (e.g. Munkholm et al., 2013; Cui et al., 2014; Cherubin et al., 2017) and is known to correlate with physical (Guimarães et al., 2011, 2013; Pulido Moncada et al., 2014)

Correspondence: J. P. Emmet-Booth.

E-mail: jeremy.emmet-booth@ucdconnect.ie

Received July 2017; accepted after revision December 2017 and biochemical (Askari et al., 2015) soil quality indicators. VESS is easy to deploy (Guimarães et al., 2013; Pulido Moncada et al., 2014), with a five-point scale, and is usable by a range of stakeholders (Ball et al., 2007).

VESS, and the Peerlkamp method from which it is derived (Ball et al., 2007), focuses on tilled soil under arable management (Peerlkamp, 1959; Ball et al., 2007). Peerlkamp (1959) noted the need for modification for grasslands, echoed by Cui et al. (2014). In pastures, the mechanisms of structural morphology differ due to the root development of a permanent crop, infrequent cultivation and the action of livestock. Compaction in tilled soils tends to be at depth due to heavy machinery, while annual tillage operations modify soil surface structure (Batey, 2009). Grassland compaction may result from machinery or livestock (Creamer et al., 2010; Newell-Price et al., 2013). Heavy machinery passes, notably on wet soils, may gradually cause compaction at 
depth. Livestock treading may cause surface poaching or pugging (Drewry, 2006). Such processes are linked with increased bulk density, shear and penetration resistance and changes in porosity (Kurz et al., 2006; Herbin et al., 2011; Phelan et al., 2013), notably reductions in macro-porosity (Houlbrooke et al., 2011). However, subsurface structural degradation may not be as visible as in arable soils (RogerEstrade et al., 2004).

Cui et al. (2014) identified problems using VESS in pastures where the grass root-mat was difficult to assess. This layer is the soil-atmosphere interface directly influencing infiltration and gaseous exchange (Alderfer \& Robinson, 1947; Hillel, 1998), impacting soil functioning and pollution, notably nutrient run-off (Kurz et al., 2006; Bilotta et al., 2007) and greenhouse gas fluxes (Ball et al., 2012; Ball, 2013). For example, Batey \& Killham (1986) described nitrogen losses from anoxic zones directly below hoof prints. The root-mat is damaged directly by livestock treading (Nie et al., 2001) and machinery operations, with compacting forces progressively transmitted downwards through the soil. Natural root-mat rejuvenation will occur (Drewry, 2006), however may take time (Herbin et al., 2011). The recovery of subsurface structure is more gradual (Drewry, 2006); therefore, the root-mat and structure below can represent different morphological timescales. The root-mat evaluation indicates recent impacts, subsurface compaction likelihood, soil-atmosphere interface functioning and immediate management requirements. Subsurface evaluation indicates the net result of long-term management.

Visual evaluation of soil structure generates a summarizing structural quality (Sq) score between 1 (optimal) and 5 (poor) (Ball et al., 2007; Guimarães et al., 2011), typically defined in terms of arable soil management. Sq 4 was the highest score from an Irish grassland survey (Cui et al., 2014), while Ball et al. (2017) reported $\mathrm{Sq} 4.2$ associated with imposed livestock and machinery compaction in Scotland. This suggests the damage represented by Sq 5 for arable soils is not necessarily relevant for temperate maritime grassland. Furthermore, the interpretation of $\mathrm{Sq} 4$ and 5 is the same, requiring immediate management change to improve soil structural quality (Ball et al., 2007), potentially making Sq 5 redundant for grasslands.

Despite these limitations, VESS has worked well for grassland. Newell-Price et al. (2013) found the Peerlkamp method related to bulk density, while VESS scores related to bulk density, total carbon, nitrogen (Cui et al., 2014) and microbial activity (Cui \& Holden, 2015). VESS has been successfully used to identify structural degradation from cattle trampling and potential for nitrous oxide $\left(\mathrm{N}_{2} \mathrm{O}\right)$ fluxes (Ball et al., 2017). VESS scores corresponded to eleven grassland soil quality indicators including aggregate size distribution, bulk density $\left(\rho_{\mathrm{b}}\right)$ and potassium (Askari \& Holden, 2014). Therefore, VESS is a solid foundation to build a VSE technique for grassland. A version of VESS was developed for grasslands as part of the 'Healthy Grassland Soils' project (AHDB, 2014), but does not specifically consider the root-mat and has not appeared in the peer-reviewed literature. Concern about compaction of grasslands in Europe (Bilotta et al., 2007; Creamer et al., 2010; Newell-Price et al., 2013) means that understanding the implications of root-mat damage, poaching and pugging is important for soil management. A VSE method to specifically identify and assess anthropogenic influences on grassland soil structural quality would aid best-practice farm management.

The aim of this work was to develop GrassVESS, designed specifically for structural quality evaluation of pasture soils incorporating a root-mat assessment. The method needed to be quick and easy to deploy by a range of users with minimal training to provide real-time management support. The objectives were then to evaluate GrassVESS by (i) an operator focus group to examine usability and reproducibility given a small amount of training and (ii) comparison with VESS and quantitative indicators of structural quality in a grassland survey.

\section{Materials and Methods}

\section{The development of GrassVESS}

GrassVESS uses the diagnostic properties and scoring of VESS (Ball et al., 2007; Guimarães et al., 2011). VESS requires an intact block of topsoil to $\approx 25 \mathrm{~cm}$ depth to be extracted by spade, examined and evaluated for visible layers. Each layer is manually broken up, and aggregate size and shape, porosity, rupture resistance and rooting are compared with a score sheet to decide an Sq score, which are combined for a sample score. GrassVESS (Figures 1 and 2) uses a separate classification procedure for the root-mat and an illustrated flow chart for the lower portion of the sample block. Sq 4 is the highest score possible. The flow chart progresses through soil properties to arrive at a score. Other modifications of VESS are $\mathrm{Sq} 2$ aggregates that can be subangular; in $\mathrm{Sq} 4$, all roots need not be restricted to macropores; and the aggregate size threshold was reduced from $>10 \mathrm{~cm}$ to $>7 \mathrm{~cm}$ (Guimarães-personal communication). A record sheet (Figure 3) was also developed.

An initial access pit, deeper and wider $(\approx 25 \mathrm{~cm}$ wide $\times$ $25 \mathrm{~cm}$ deep) than the sample block, is required to extract an intact sample block $(\approx 15 \mathrm{~cm}$ wide $\times 15 \mathrm{~cm}$ thick $\times 20 \mathrm{~cm}$ deep). The sample block is placed on a plastic tray or sheet and split open to reveal the root-mat and lower portion, using a knife to cut roots if necessary. Where no distinct root-mat is evident, the upper $6 \mathrm{~cm}$ is assessed as such. The lower portion is assessed first, followed by the root-mat generating separate $\mathrm{Sq}$ and root-mat $(\mathrm{Rm})$ scores. 


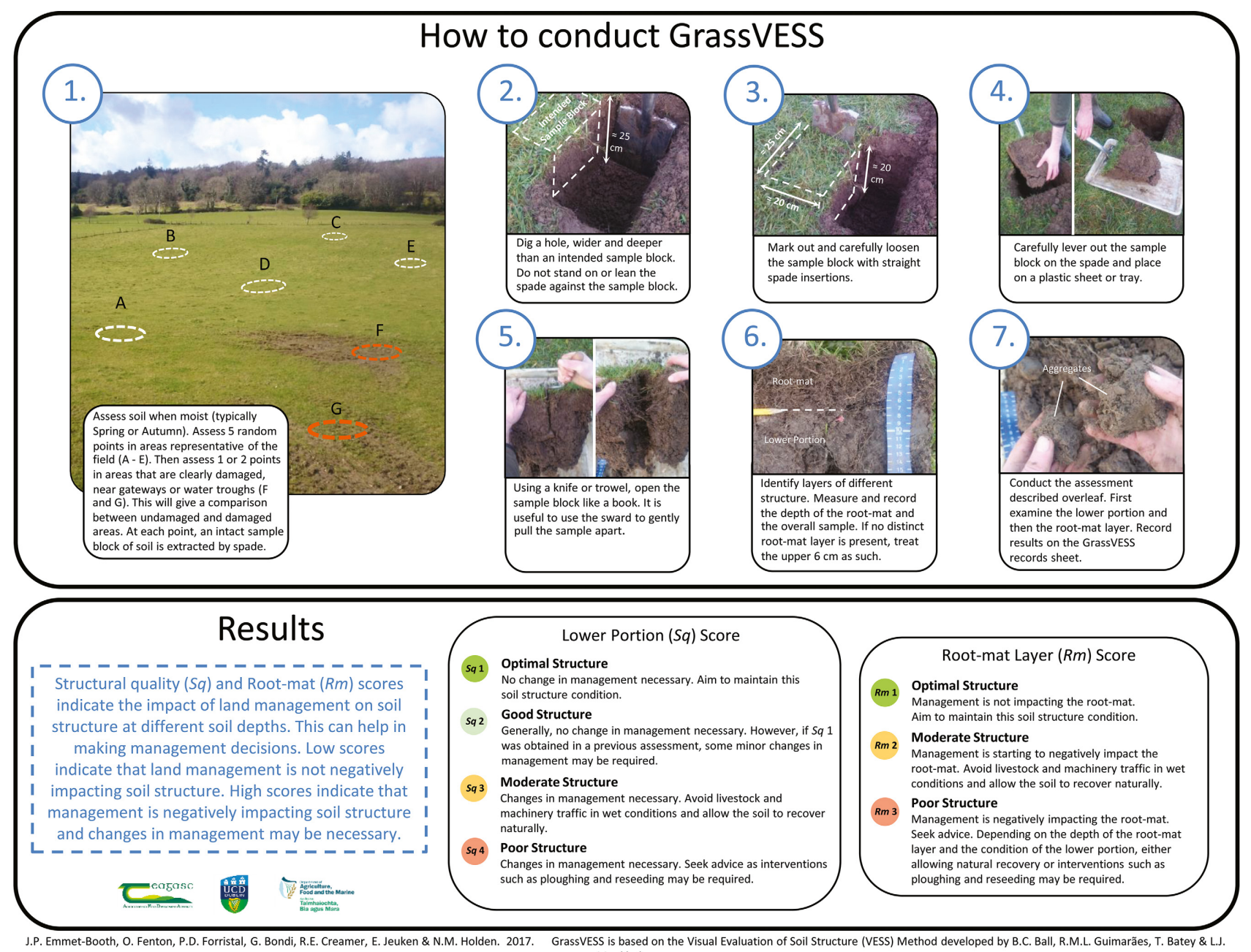

Figure 1 GrassVESS front page (intended for production on A3 size paper) giving instructions on procedure deployment and result explanations.

\section{The evaluation of Grass VESS}

The method was evaluated by a focus group to assess ease of deployment and reproducibility and a grassland survey (trained operator) to test for contrasting soils and conditions.

The focus group, conducted at the UCD Lyons Research Farm, Co. Kildare, Ireland (53.299200 N, -6.536339 W), in April 2017, consisted of seven graduate students with varying knowledge of soil, given 60 min training and a field demonstration. In a single grazed paddock, with a silty, silty clay loam (Collins \& Brickley, 1970) at an approximate soil moisture deficit (SMD) of $37 \mathrm{~mm}$ (Met Éireann, 2017), each member of the group used VESS and GrassVESS in a $50 \mathrm{~m}^{2}$ area. No background history about the methods was provided. After deploying both methods, a scored questionnaire was completed about ease of deployment, how each method dealt with technical information, navigation of the score sheet and the assessment of the root-mat. Arithmetic mean scores were calculated, and qualitative responses were used to interpret the meaning.

The grassland survey was conducted across Ireland (Figure 4) from April to June and September to October 2015. Sites represented a range of agro-climatic regions (Holden \& Brereton, 2004) and soils classified as poorly drained surface water gleys (Stagnosols) $(n=10)$ or welldrained brown earths (Cambisols) $(n=20)$ (Creamer et al., 2014). Particle size distribution was measured by pipette (British Standards Institution, 1989) from bulk samples taken from the upper horizon of each site (Table 1). Management intensity was determined using the framework of Cui et al. (2014): farm stocking rate (Livestock Units $(\mathrm{LU}) / \mathrm{ha}$ ), time since last reseeding (years) and inorganic nitrogen $(\mathrm{kg} \mathrm{N} / \mathrm{ha} / \mathrm{yr})$ (Table 4$)$. The score for each attribute 


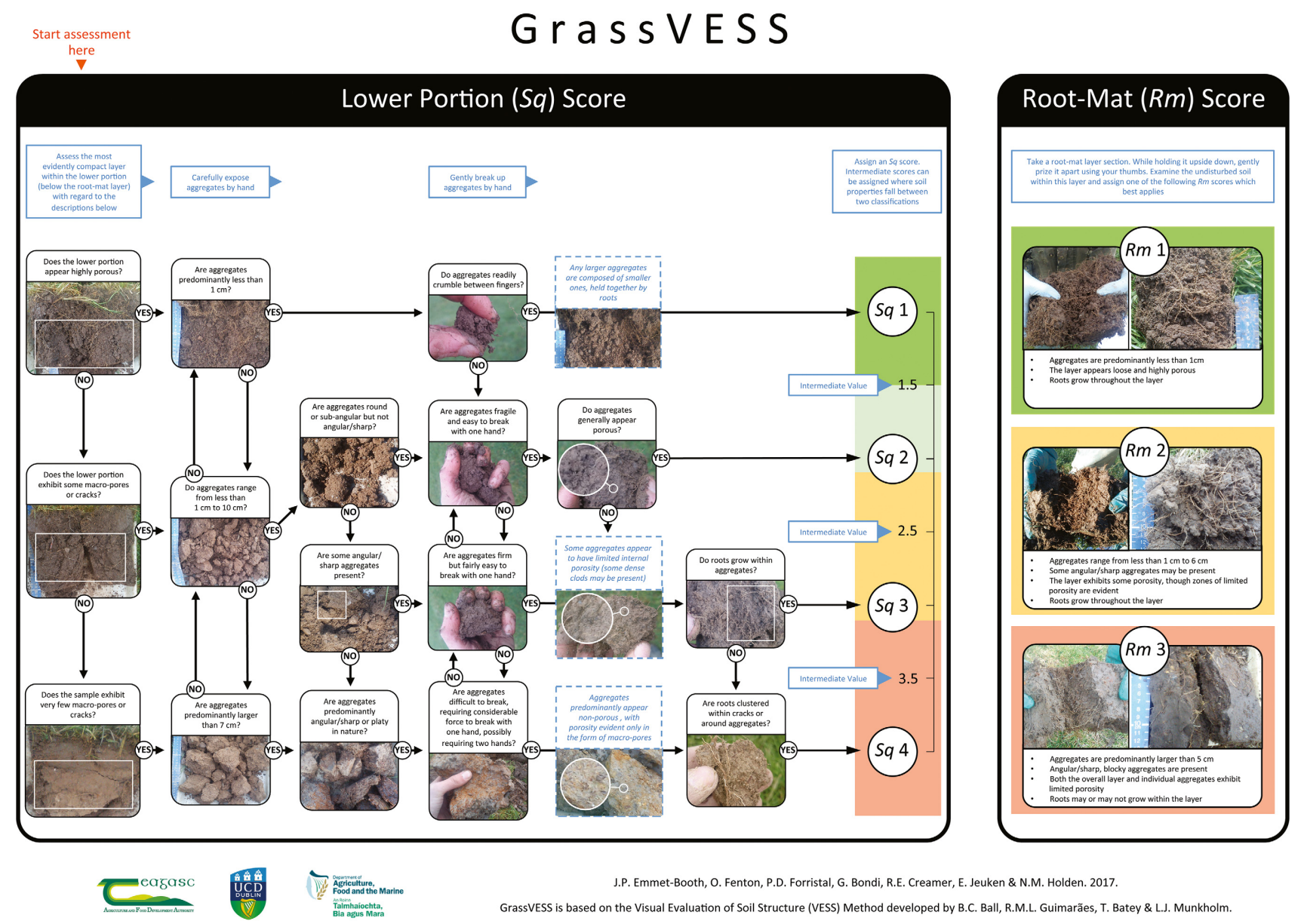

Figure 2 GrassVESS back page (intended for production on A3 size paper) outlining the 'lower portion' classification flow chart and 'root-mat' classification system.

was plotted on $x$-, $y$ - and $z$-axes with the resulting position along the cubic diagonal used to calculate an integer intensity score of $1-5$.

At each site, a $30 \mathrm{~m}^{2}$ area was marked in a typical field area within which three sample points were located. A sampling point was also located in an atypical area near a water tough or gateway. At each point, VESS, GrassVESS, quantitative indicators of soil structure and pugging scores (Nie et al., 2001) were obtained. The latter involved the visual estimation of exposed soil (damaged sward) area within a 1-m quadrat, generating scores between 1 and 5, where 5 indicated $100 \%$ exposure. The quantitative indicators were surface roughness using the chain reduction (Saleh, 1994) calculated from six measurements, with a 1-m bicycle chain laid over the soil surface along a metre stick and the resulting chain length recorded. $\rho_{\mathrm{b}}$, total- $(\varepsilon)$ and macro-porosity $\left(\varepsilon_{\text {mac }}\right)$ were determined from $2 \times \varnothing 5 \mathrm{~cm} \mathrm{x} \mathrm{h} 5 \mathrm{~cm}$ intact cores at 5$10 \mathrm{~cm}$ and $10-20 \mathrm{~cm}$ depth. The latter were treated according to Flint \& Flint (2002) and Piwowarczyk et al. (2011) where sample bases were covered with open cloth $(1 \mathrm{~mm})$ secured with steel clips. Samples were saturated by placing on racks held within sealable containers into which water was added to $\leq 1 \mathrm{~mm}$ of sample surfaces and left for $64 \mathrm{~h}$. Samples were then allowed to drain by gravity on racks within empty sealed containers, maintained at $4{ }^{\circ} \mathrm{C}$ in a dark room, for $24 \mathrm{~h}$ at which point macro-pores were considered to have drained. Although this method does not reflect the boundary conditions in the field for free drainage after saturation and the value of macro-porosity will tend to be underestimated, it still allows for adequate assessment of the different structural conditions. Finally, samples were dried at $105{ }^{\circ} \mathrm{C}$ for $44 \mathrm{~h}$. Sample mass was determined at each stage, allowing calculation of $\rho_{\mathrm{b}}$, volumetric water content $(\theta)$ and therefore the estimation of $\varepsilon$ and $\varepsilon_{\text {mac }}$.

Arithmetic mean values for each property (VESS, GrassVESS, pugging score, chain reduction, $\left.\rho_{\mathrm{b}}, \varepsilon, \varepsilon_{\mathrm{mac}}\right)$ were calculated using the three sampling points as replicates per site. As GrassVESS does not generate a summarizing score, VESS Layer 1 (L1) and Layer 2 (L2) scores were compared with GrassVESS Rm and lower portion (LP) scores. Where three VESS structural layers were observed, scores for Layers 2 and 3 were combined. For both VESS and GrassVESS, Sq scores of $\leq 2$ were classified as good structural quality, $>2$ to $\leq 3$ as moderate and $>3$ as poor (Ball 


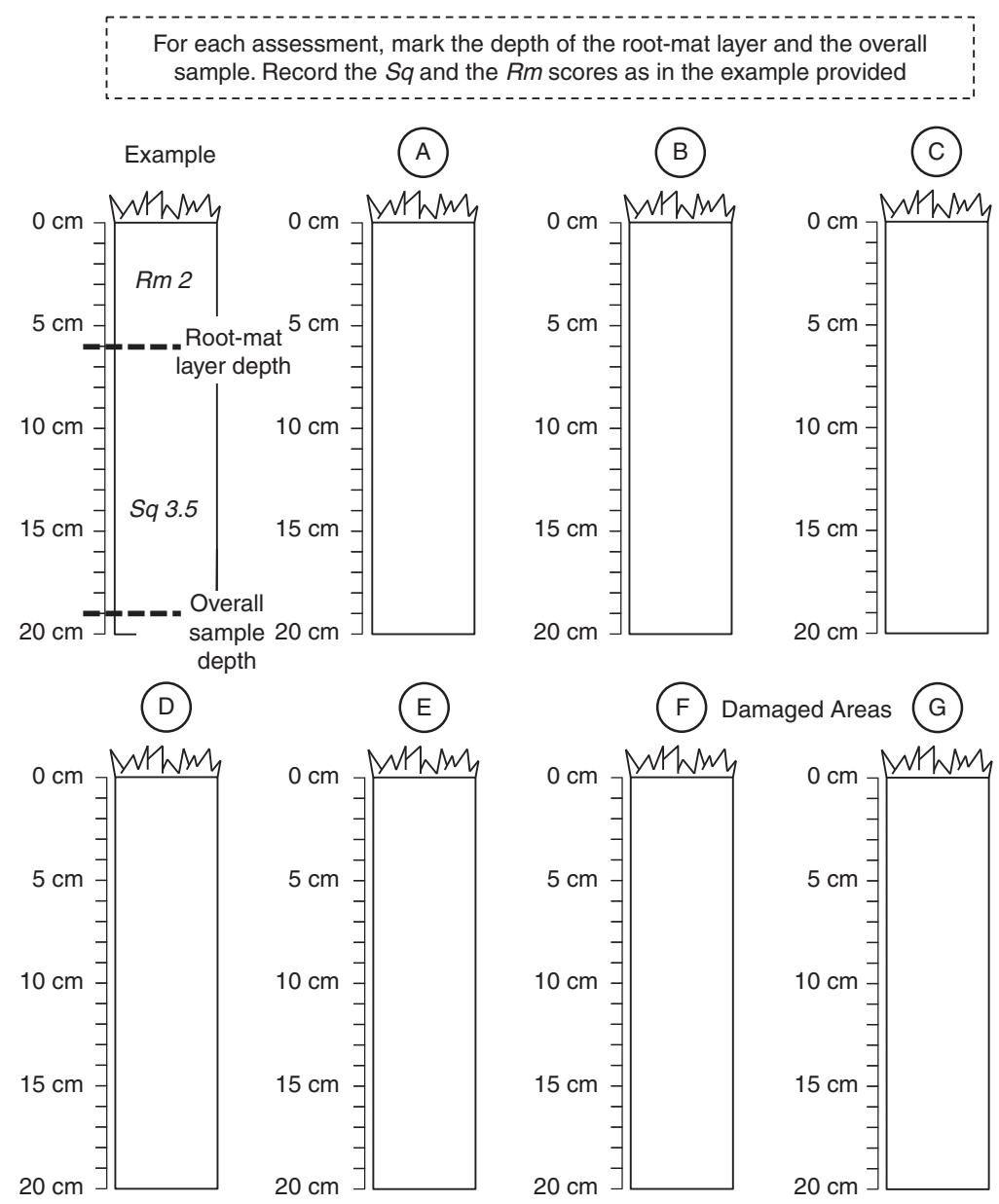

Figure 3 GrassVESS record sheet, designed to clearly illustrate results, using an approach devised by Guimarães et al. (2013).

et al., 2007). Rm scores of 1, 2 and 3 were classified as good, moderate and poor respectively with site mean values rounded to nearest whole numbers.

All statistical analysis was conducted using R Studio 3.1.1 ( $\mathrm{R}$ Core Team, 2014) with nonparametric (Wilcoxon signedrank, Mann-Whitney $U$, Spearman's rank, Kruskal-Wallis) tests. For management intensity, mean measurement values for each intensity class were determined and trends visually identified.

\section{Results}

\section{Operator focus group}

Most (6 of 7) of the focus group had some experience of soil, ranging from desk research to laboratory analysis. None were familiar with VSE. Both procedures resulted in similar scores for below root-mat structure ( $\mathrm{Sq} 2.5)$; however, surface layer evaluation differed (Table 2; VESS L1
$\mathrm{Sq}=2.7$, GrassVESS Rm $=1.9$ ). VESS resulted in a greater range of scores and scored slightly worse for ease of deployment $\quad$ (Table 2; $\quad$ VESS $=2.7, \quad$ GrassVESS $=2.1$ ) Operators suggested that VESS was more detailed, but the concurrent assessment of properties was difficult in practice. GrassVESS was described as complex, although the flow chart aided score determination. The presentation of technical information (e.g. aggregation, sizes, strengths) was easier to follow for GrassVESS (Table 2; $\operatorname{VESS}=2.7$, GrassVESS = 1.6), with the images for each decision highlighted as beneficial. Methods were similarly ranked for ease of using the score sheets (Table 2; $\operatorname{VESS}=3$, GrassVESS $=2.9$ ). Operators noted that VESS facilitated independent assessment of each property without considering previous diagnoses, yet classification was described as too rigid. GrassVESS required the continuous reconsideration of previous decisions, but the decision structure was easier to follow. The root-mat evaluation was more difficult by VESS (Table 2; VESS $=4$, GrassVESS 1.4) with diagnostic 


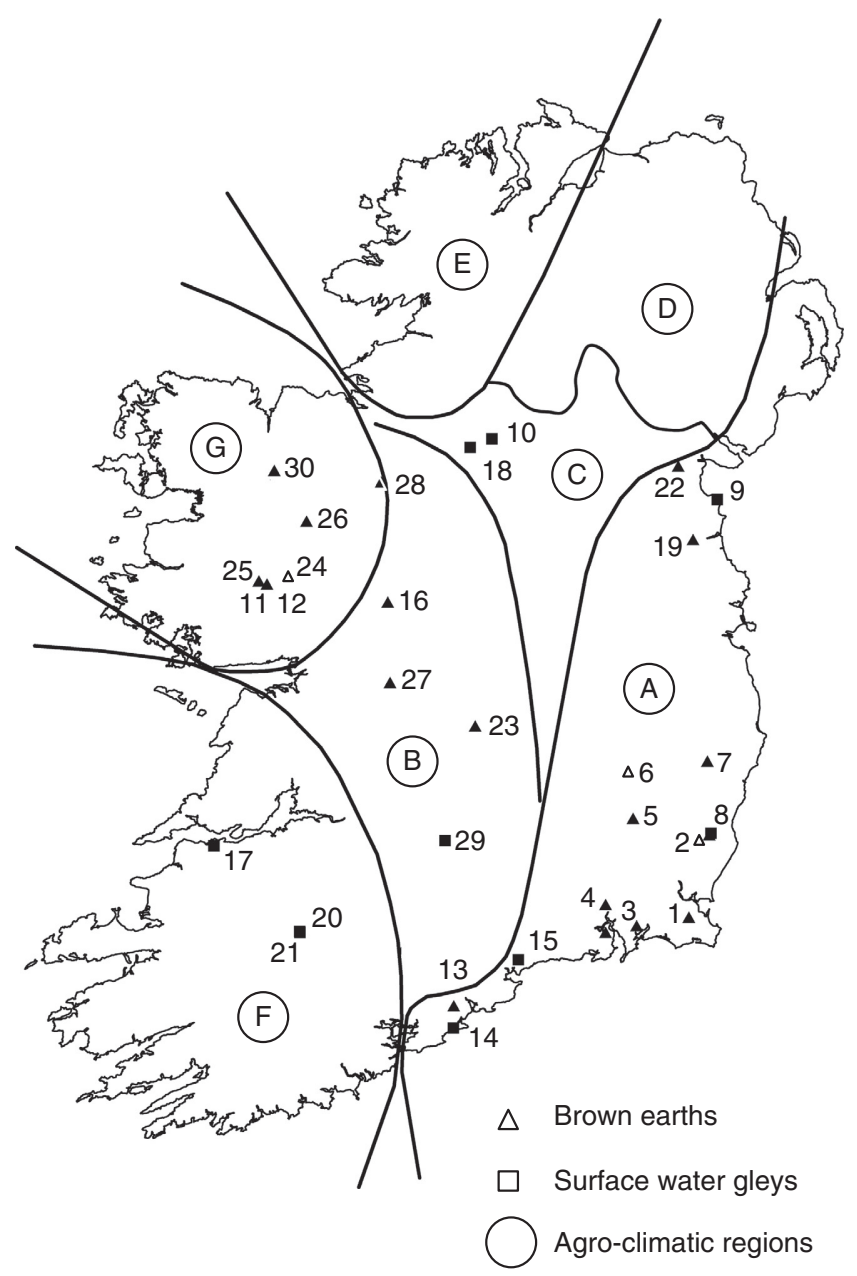

Figure 4 Survey sites across agro-climatic regions of Ireland according to Holden \& Brereton (2004).

descriptions indicated as not being related to the root-mat, and GrassVESS described as better. For most operators (5 of 7), GrassVESS was quicker (Table 2), while 4 of 7 indicated that they would be more inclined to use GrassVESS (Table 2) reasons given related to the images to support decisions and clear directions.

\section{Field survey}

During sampling, $\theta(10-20 \mathrm{~cm}$ depth) ranged from 0.22 to $0.56 \mathrm{~g} / \mathrm{cm}^{3}$ with the SMD outlined for each site (Table 1). Both VSE methods for all soil layers indicated that soil structural quality was poorer in atypical areas, a finding supported by pugging scores and all quantitative measurements including chain reduction, $\rho_{\mathrm{b}}, \varepsilon$ and $\varepsilon_{\text {mac }}$ (Table 3). Root-mat depth was significantly greater in typical areas (mean of $5.7 \mathrm{~cm}$ ), and in atypical areas, GrassVESS indicated greater root-mat damage than VESS for the surface layer. Rm scores classified $18 \%$ more of the atypical
Table 1 Soil texture data and predicted soil moisture deficit at time of sampling for field survey sites

\begin{tabular}{|c|c|c|c|c|}
\hline Site & Sand $(\%)$ & Silt $(\%)$ & Clay (\%) & $\mathrm{SMD}^{\mathrm{a}}(\mathrm{mm})$ \\
\hline 01 & 26.4 & 47.6 & 26 & 29 \\
\hline 02 & 41.8 & 39.2 & 19 & 25 \\
\hline 03 & 43.3 & 31.7 & 25 & 3 \\
\hline 04 & 34.9 & 40.1 & 25 & 9 \\
\hline 05 & 33.9 & 40.1 & 26 & 10 \\
\hline 06 & 68.2 & 16.8 & 15 & 11 \\
\hline 07 & 30.3 & 45.7 & 24 & 11 \\
\hline 08 & 33.8 & 39.2 & 27 & 5 \\
\hline 09 & 26.6 & 36.4 & 37 & 27 \\
\hline 10 & 46.7 & 37.3 & 16 & 9 \\
\hline 11 & 42.3 & 31.7 & 26 & 3 \\
\hline 12 & 44.2 & 30.8 & 25 & 5 \\
\hline 13 & 46.4 & 33.6 & 20 & 18 \\
\hline 14 & 46.1 & 28.9 & 25 & 22 \\
\hline 15 & 40.0 & 42.0 & 18 & 22 \\
\hline 16 & 54.1 & 28.9 & 17 & 32 \\
\hline 17 & 26.0 & 42.0 & 32 & 30 \\
\hline 18 & 43.1 & 28.9 & 28 & 8 \\
\hline 19 & 34.9 & 40.1 & 25 & -10 \\
\hline 20 & 22.6 & 50.4 & 27 & 4 \\
\hline 21 & 26.6 & 49.5 & 24 & 6 \\
\hline 22 & 35.6 & 35.5 & 29 & 12 \\
\hline 23 & 45.3 & 31.7 & 23 & 9 \\
\hline 24 & 42.6 & 36.4 & 21 & 1 \\
\hline 25 & 43.1 & 28.9 & 28 & 1 \\
\hline 26 & 49.6 & 35.5 & 15 & 3 \\
\hline 27 & 31.1 & 42.9 & 26 & 6 \\
\hline 28 & 45.2 & 30.8 & 24 & 5 \\
\hline 29 & 12.6 & 49.5 & 38 & 10 \\
\hline 30 & 58.6 & 22.4 & 19 & 0 \\
\hline
\end{tabular}

${ }^{\mathrm{a}} \mathrm{SMD}=$ Soil Moisture Deficit as predicted by Met Éireann (2017).

areas as severely damaged compared with VESS L1 Sq scores $(n=28)$. VESS Sq scores slightly better correlated with pugging scores $\left(r_{s}=0.52\right.$, sig $\left.=0.007\right)$ than GrassVESS Rm scores $\left(r_{s}=0.49\right.$, sig $\left.=0.01\right)$ for atypical areas. VESS L2 and GrassVESS LP Sq scores were significantly correlated $\left(r_{s}\right.$ $=0.73, P=<0.01)$ with $71 \%$ of atypical areas classified as poor structural quality by both $(n=28)$. For typical areas, neither VESS L1 Sq $(U=58.5$, sig $=0.07)$ nor GrassVESS $\mathrm{Rm} \quad(U=70.5, \quad$ sig $=0.17) \quad$ scores showed significant difference by soil type. A significant difference was observed for VESS L2 $(U=26.5$, sig $=0.001)$ and GrassVESS LP $(U=31.5$, sig $=0.003)$ by soil type. VESS classified $30 \%$ of brown earth soils as having poor structure below the rootmat structure, but GrassVESS classified $40 \%$ as poor structure, while both classified $80 \%$ of surface water gleys as having poor below root-mat structure.

Considering all field areas, significant $(P=<0.01)$ correlations were found between VESS L1 Sq and GrassVESS Rm scores $\left(r_{s}=0.89\right)$ and VESS L 2 and 


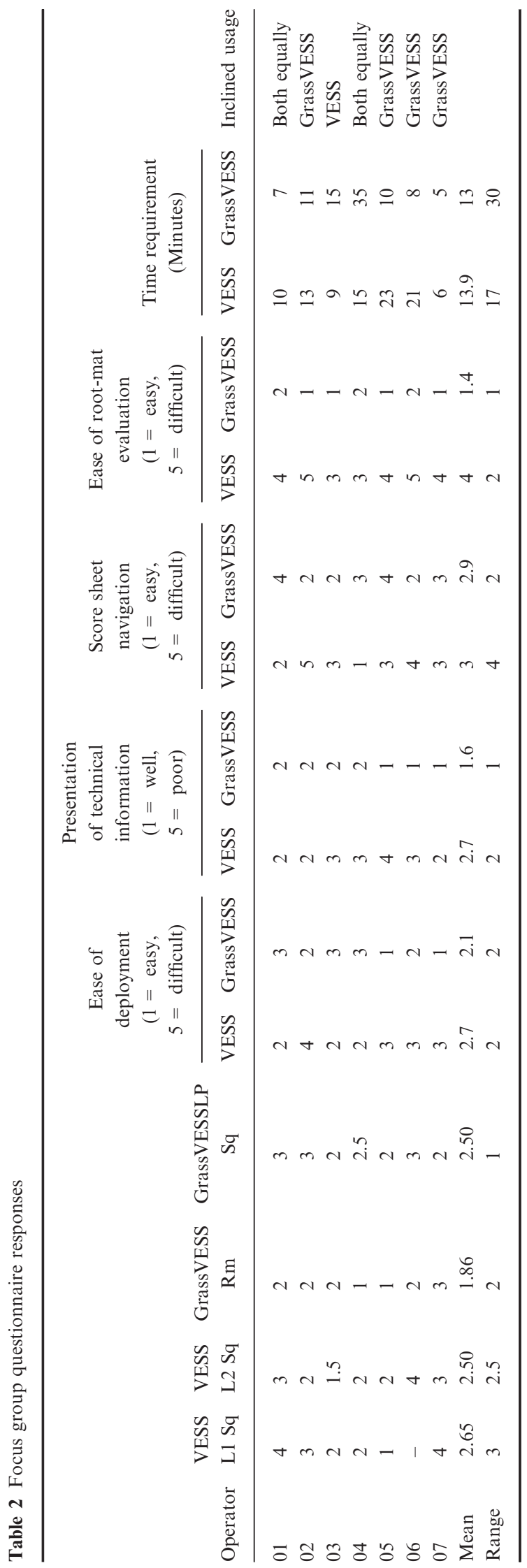

GrassVESS LP Sq scores $\left(r_{s}=0.87\right)$. Although both significantly $(P=<0.01)$ correlated with pugging scores, GrassVESS Rm scores demonstrated a stronger relationship $\left(r_{s}=0.52\right)$ than VESS Sq scores $\left(r_{s}=0.48\right)$. No correlation was observed between pugging scores and below root-mat structure scores. For typical field areas, VESS and GrassVESS indicated similar structural conditions. VESS classified $80 \%$ of sites with no surface damage and $20 \%$ with moderate surface damage. GrassVESS classified 70\% with no root-mat damage and $30 \%$ with moderate root-mat damage $(n=30)$. Regarding the below root-mat soil, VESS classified $47 \%$ and GrassVESS 53\% with poor structure.

\section{Relationship with quantitative indicators and management}

$\rho_{\mathrm{b}}$ 5-10 cm, $\varepsilon_{5-10 \mathrm{~cm}}$ and chain reduction showed significant differences between typical and atypical areas (Table 3). There was a significant difference in $\rho_{\mathrm{b}}{ }_{5-10} \mathrm{~cm}$ and $\varepsilon_{5-10 \mathrm{~cm}}$ based on VESS L1 $(H=10.48, \quad$ df $=2, \quad$ sig $=0.005$; $H=12.32, \quad \mathrm{df}=2, \quad \mathrm{sig}=0.002) \quad$ and GrassVESS Rm $(H=12.38, \quad \mathrm{df}=2, \quad \mathrm{sig}=0.002 ; \quad H=14.26, \quad \mathrm{df}=2$, sig $=0.0007)$ classification, with better correspondence with GrassVESS (Figure 5). There were significant differences in $\varepsilon_{\text {mac }} 5-10 \mathrm{~cm}$ and $\varepsilon_{\text {mac }} 10-20 \mathrm{~cm}$ based on VESS L2 $(H=8.77$, $\mathrm{df}=2, \quad \mathrm{sig}=0.012 ; \quad H=9.69 \quad \mathrm{df}=2, \quad \mathrm{sig}=0.008) \quad$ and GrassVESS LP $(H=12.03$, df $=2, \operatorname{sig}=0.002 ; H=13.07$, $\mathrm{df}=2$, sig $=0.001)$ classification. Significant difference in chain reduction according to VESS L1 $(H=7.58, \mathrm{df}=2$, $\operatorname{sig}=0.02)$ and GrassVESS $\operatorname{Rm} \quad(H=8.44, \quad \mathrm{df}=2$, sig $=0.01)$ classification was observed. Chain reduction also differed significantly $(P=<0.01)$ with pugging score $(H=16.21$, df $=5)$. For typical areas, $\varepsilon_{\text {mac }}$ significantly differed at both $5-10 \mathrm{~cm}(U=148.5$, sig $=0.03)$ and 10 $20 \mathrm{~cm}(U=177.5$, sig $=0.0007)$ per soil group, with surface water gleys associated with $30 \%$ less mean $\varepsilon_{\text {mac }} 5-10 \mathrm{~cm}$ and $48 \%$ less $\varepsilon_{\text {mac }} 10-20 \mathrm{~cm}$.

For typical areas, significant differences in indicators according to management intensity factors are outlined (Table 4) although few were found. Visible trends indicated stocking rate to have a greater impact than $\mathrm{N}$-input and reseeding. VESS L1 and GrassVESS Rm scores both indicated that root-mat structure was negatively affected by increased stocking rate. $\rho_{\mathrm{b}}, \varepsilon$ and pugging scores indicated similar trends. VESS L2 and GrassVESS LP Sq scores suggested that at higher stocking rates (classes 2 and 3) structural damage occurred at deeper soil depths. With increasing years since last reseeding, $\rho_{\mathrm{b}} 5-10 \mathrm{~cm}$ decreased and $\varepsilon_{\text {mac }} 10-20 \mathrm{~cm}$ increased. VESS L2 and GrassVESS LP scores suggested structural damage associated with the least time since reseeding (class 3). VESS L1 scores indicated a decline in soil quality with increased overall management intensity, as reflected in $\rho_{\mathrm{b}} 5-10 \mathrm{~cm}$ and $\varepsilon_{5-10 \mathrm{~cm}}$, but this was not reflected in GrassVESS Rm scores. Both VESS L2 and GrassVESS LP scores indicated a gradual decline in quality 
Table 3 Relationship between measurements and field area

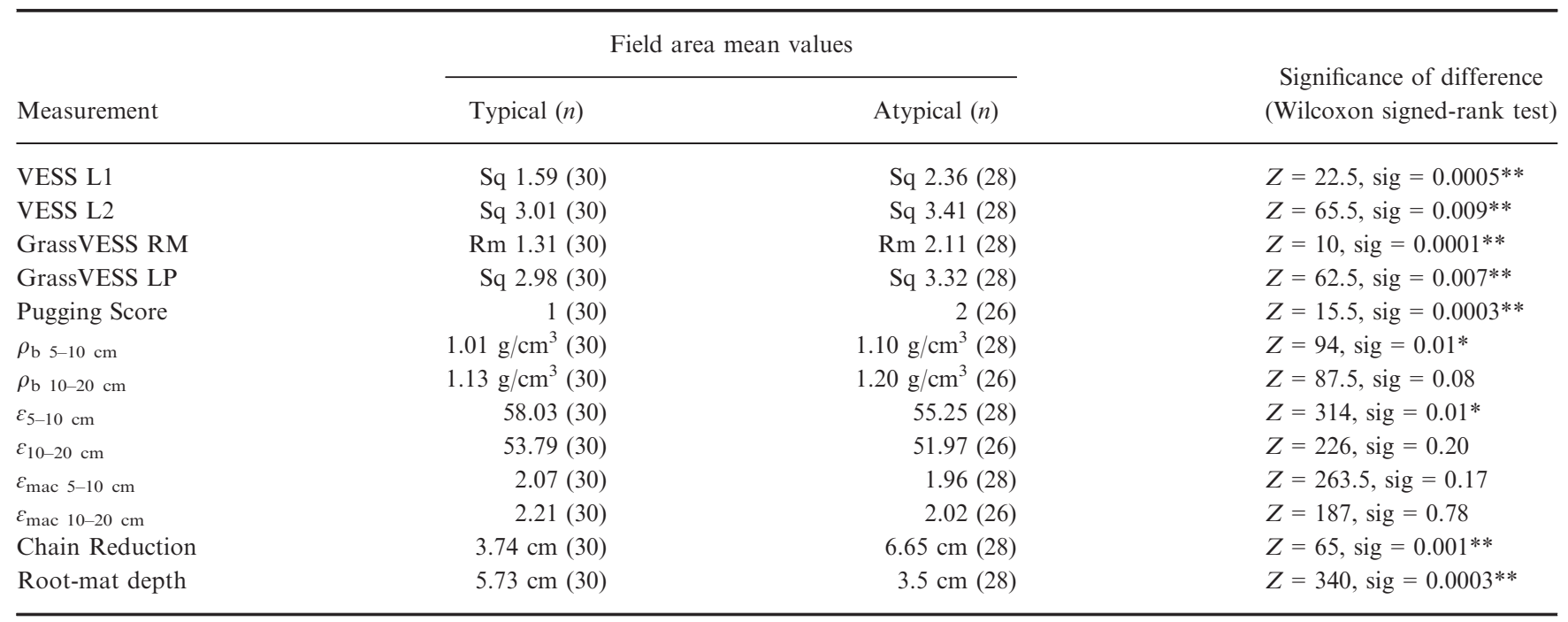

** Significant at $P=0.01$; Significant at $P=0.05$.
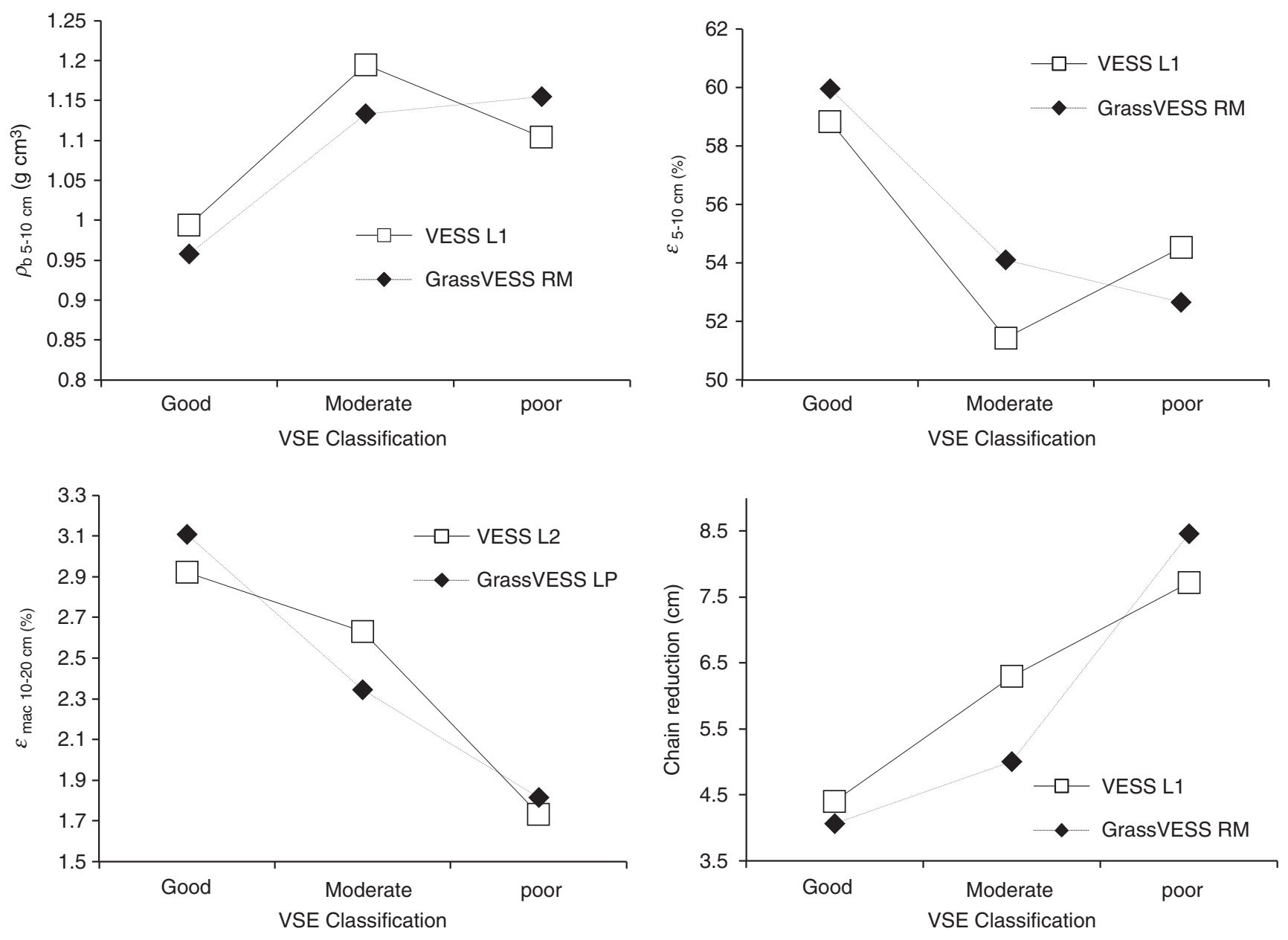

Figure 5 Mean quantitative indicator values according to VSE structural quality classification. 
Table 4 Mean measurement values per management intensity class for typical field areas

\begin{tabular}{|c|c|c|c|c|c|c|c|c|c|c|c|}
\hline Intensity class & $\begin{array}{c}\text { VESS } \\
\text { L1 (Sq) }\end{array}$ & $\begin{array}{c}\text { VESS } \\
\text { L2 (Sq) }\end{array}$ & $\begin{array}{c}\text { Grass VESS } \\
\text { Rm (Rm) }\end{array}$ & $\begin{array}{c}\text { Grass VESS } \\
\text { LP }(\mathrm{Sq})\end{array}$ & $\begin{array}{c}\rho_{\mathrm{b} 5-10 \mathrm{~cm}} \\
\left(\mathrm{~g} / \mathrm{cm}^{3}\right)\end{array}$ & $\begin{array}{c}\rho_{\mathrm{b} 10-20 \mathrm{~cm}} \\
\left(\mathrm{~g} / \mathrm{cm}^{3}\right)\end{array}$ & $\begin{array}{l}\varepsilon_{5-10} \\
\mathrm{~cm}(\%)\end{array}$ & $\begin{array}{l}\varepsilon_{10-20} \\
\mathrm{~cm} \mathrm{( \% )}\end{array}$ & $\begin{array}{c}\varepsilon_{\operatorname{mac} 5-10} \\
\mathrm{~cm}(\%)\end{array}$ & $\begin{array}{c}\varepsilon_{\mathrm{mac}} 10-20 \\
\mathrm{~cm}(\%)\end{array}$ & $\begin{array}{l}\text { Pugging } \\
\text { score }\end{array}$ \\
\hline Stocking R. (LU/ha) & $* \mathrm{a}$ & & $* \mathrm{~b}$ & & & & & & & & \\
\hline $1(<1.5)$ & 1.4 & 2.7 & 1.2 & 2.7 & 0.96 & 1.10 & 59.66 & 54.92 & 2.30 & 2.82 & 0 \\
\hline $2(1.5-2.5)$ & 1.6 & 3.1 & 1.3 & 3.1 & 1.00 & 1.13 & 58.54 & 54.18 & 1.94 & 1.81 & 1 \\
\hline $3(\geq 2.5)$ & 2.2 & 3.3 & 1.8 & 3.1 & 1.13 & 1.33 & 52.43 & 49.74 & 2.16 & 2.80 & 2 \\
\hline $2(10-20)$ & 1.4 & 2.9 & 1.8 & 2.9 & 0.99 & 1.10 & 58.57 & 55.70 & 2.35 & 2.01 & 2 \\
\hline $3(0-10)$ & 1.9 & 3.3 & 1.4 & 3.2 & 1.14 & 1.14 & 53.39 & 53.23 & 1.85 & 1.76 & 2 \\
\hline N Input (kg/ha) & & & $*_{\mathrm{c}}$ & & & & & & & & \\
\hline $1(0-43)$ & 1.9 & 2.5 & 1.9 & 2.4 & 1.03 & 1.12 & 58.59 & 54.25 & 1.73 & 2.82 & 1 \\
\hline $2(43-129)$ & 1.5 & 2.9 & 1.2 & 2.9 & 0.96 & 1.11 & 59.59 & 54.24 & 2.03 & 2.03 & 0 \\
\hline 4 & 1.6 & 3.2 & 1.4 & 3.2 & 1.02 & 1.11 & 57.34 & 54.53 & 2.19 & 2.38 & 1 \\
\hline 5 & 2 & 3.4 & 1.5 & 3.3 & 1.18 & 1.24 & 51.35 & 49.61 & 1.76 & 1.61 & 1 \\
\hline
\end{tabular}

*Significant at $P=0.05 .{ }^{\mathrm{a}} H=6.2135, \mathrm{df}=2, \mathrm{sig}=0.045 ;{ }^{\mathrm{b}} H=6.8128, \mathrm{df}=2, \mathrm{sig}=0.033 ;{ }^{\mathrm{c}} H=6.8943, \mathrm{df}=2, \mathrm{sig}=0.032 ;{ }^{\mathrm{d}} H=8.0827$, $\mathrm{df}=3, \mathrm{sig}=0.044 ;{ }^{\mathrm{e}} H=9.1279, \mathrm{df}=3$, sig $=0.028$.

with overall management intensity, not reflected in quantitative measurements taken at $10-20 \mathrm{~cm}$ depth.

\section{Discussion}

The aim of this work was to develop a VSE method specifically for grassland appropriate for a range of users and real-time soil management support. The most important requirement was to properly address the contrasting structure and temporal morphology of the root-mat and lower layers. This was achieved by separating the descriptions for each layer. The identification and assessment of separate layers when using VSE have been widely advocated (Giarola et al., 2010; Guimarães et al., 2011; Cherubin et al., 2017), notably in grassland (Newell-Price et al., 2013; Ball et al., 2017) because understanding the position of compacted layers aids management (Guimarães et al., 2013; Ball et al., 2017). A previous survey of Irish grasslands (Cui et al., 2014) and this survey show that rootmats are typical of temperate grasslands, as also reported for tropical pastures (Cherubin et al., 2017; Guimarães et al., 2017). Root-mats appear only absent with severe stress, and when missing, GrassVESS treats the upper $6 \mathrm{~cm}$ of soil as a 'root-mat zone', indicative of severe damage. GrassVESS addresses the typical structure of pasture soils found in many parts of the world, and because it is based on VESS, which has been used globally (e.g. Munkholm et al., 2013; Pulido Moncada et al., 2014; Guimarães et al., 2017), GrassVESS is potentially usable for any grassland soil.
Further testing of the detail of GrassVESS in other regions is a critical next step in its development.

The focus group indicated that GrassVESS greatly aided assessment compared with VESS. The flow chart was designed to rapidly find the correct classification starting from inter-aggregate porosity, following Shepherd (2009). The use of questions with only two answers at each decision point helps the operator to then focus on one property at a time. It is potentially difficult to specify each question to be universal for all users, so further global testing is required. The inclusion of images is beneficial to ease engagement with technical detail for a range of users. For inexperienced or infrequent operators, the flow chart approach of GrassVESS may make it be more suitable than VESS. The focus group responses supported the design, indicating that some users are happy with the flexibility of the VESS, most preferred the structure of GrassVESS. The flow chart might be more complex, but reduces uncertainty as indicated by the lower variation of scores with GrassVESS.

The field survey indicated that VESS and GrassVESS can lead to similar conclusions. Both techniques identified poorer structural quality in atypical areas, although not significantly reflected in all quantitative measurements. Both methods might underestimate structural quality in grasslands, but given the body of evidence associated with VESS (e.g. Guimarães et al., 2013; Munkholm et al., 2013; Askari et al., 2015), it is more likely that the quantitative measurements do not reflect the integration of attributes inherent in VSE. The strong relationship between VESS L2 and GrassVESS LP was achieved because the flow chart went through many 
iterations before deployment to ensure a similar result was obtained. The VESS L1 and GrassVESS Rm results were different, with GrassVESS Rm better correlated with pugging. VESS L1 indicated a gradual decline in quality with management intensity not reflected by GrassVESS Rm. However, $\rho_{\mathrm{b}} 5-10 \mathrm{~cm}$ and $\varepsilon_{5-10 \mathrm{~cm}}$, both indicators of interface, function better related to GrassVESS Rm, suggesting the system may be more suitable for predicting soil functioning.

Shepherd (2009) and Ball et al. (2017) suggested that VSE can be used to identify conditions that enhance $\mathrm{N}_{2} \mathrm{O}$ fluxes and surface run-off. Using Rm scores for early warning of subsurface compaction, nutrient use inefficiency and environmental degradation warrants research. For example, fertilizer or slurry application may be inappropriate on areas classified as Rm 3, associated with lower porosity (Figure 5), higher pugging scores (less vegetative cover) and theoretically poor infiltration and aeration, thus potentially encouraging run-off and denitrification (Alderfer \& Robinson, 1947; Ball, 2013; Ball et al., 2017).

\section{Conclusion}

GrassVESS was specifically developed for the evaluation of temperate maritime managed grasslands and may be suitable for use in other regions with grazed pastures. GrassVESS was found to be quick, straightforward and reproducible, more so than VESS. This was related to the specific rootmat evaluation system and the decision structure with supporting images used to direct the operator through the scoring decisions. Less variation between operators and greater certainty when scoring should be achieved. Therefore, GrassVESS can be used by a range of users on an ongoing basis to aid real-time grassland soil management.

\section{Acknowledgements}

This work forms part of the SQUARE Project, funded by the Irish Department of Agriculture, Food and the Marine (Ref. 13/S/468). The authors thank B.C. Ball, R.M.L. Guimarães, D. Kelleghan, M. Bacher, L. O’Sullivan, T. Cummins and L.J. Munkholm for kind help and advice.

\section{References}

AHDB. 2014. Healthy Grassland Soils - four quick steps to assess soil structure. Agriculture and Horticulture Development Board. United Kingdom. Available at: http://beefandlamb.ahdb.org. uk/grazing-club/assess-soil-structure/; accessed 25/08/2016.

Alderfer, R.B. \& Robinson, R.R. 1947. Runoff from pastures in relation to grazing intensity and soil compaction. Journal of the American Society of Agronomy, 39, 948-958.

Askari, M.S. \& Holden, N.M. 2014. Indices for quantitative evaluation of soil quality under grassland management. Geoderma, 230-231, 131-142.
Askari, M.S., Cui, J., O'Rourke, S.M. \& Holden, N.M. 2015. Evaluating soil structural quality using VIS-NIR spectrum. Soil \& Tillage Research, 146 Part A, 108-117.

Ball, B.C. 2013. Soil structure and greenhouse gas emissions: a synthesis of 20 years of experimentation. European Journal of Soil Science, 64, 357-373.

Ball, B.C., Batey, T. \& Munkholm, L.J. 2007. Field assessment of soil structural quality - a development of the Peerlkamp test. Soil Use and Management, 23, 329-337.

Ball, B.C., Cameron. K.C., M., Di, H.J. \& Moore, S. 2012. Effects of trampling of a wet dairy pasture soil on soil porosity and on mitigation of nitrous oxide emissions by a nitrification inhibitor, dicyandiamide. Soil Use and Management, 28, 194-201.

Ball, B.C., Munkholm, L.J. \& Batey, T. 2013. Applications of visual soil evaluations. Soil \& Tillage Research, 127, 1-2.

Ball, B.C., Guimarães, R.M.L., Cloy, J.M., Hargreaves, P.R., Shepherd, G.T. \& McKenzie, B.M. 2017. Visual soil evaluation: a summary of some applications and potential developments for agriculture. Soil \& Tillage Research, 173, 114-124.

Batey, T. 2009. Soil compaction and soil management - a review. Soil Use and Management, 25, 335-345.

Batey, T. \& Killham, K. 1986. Field evidence on nitrogen losses by denitrification. Soil Use and Management, 2, 83-86.

Bilotta, G.S., Brazier, R.E. \& Haygarth, P.M. 2007. The impacts of grazing animals on the quality of soils, vegetation and surface waters in intensively managed grasslands. Advances in Agronomy, 94, 237-280.

British Standards Institution. 1989. Pipette method (BS 1796, 1989). British standard methods of test for soil for civil engineering purposes. British Standards Institution.

Cherubin, M.R., Franco, A.L.C., Guimarães, R.M.L., Tormena, C., Cerri, C.E.P., Karlen, D.L. \& Cerri, C.C. 2017. Assessing soil structural quality under Brazilian sugarcane expansion areas using visual evaluation of Soil Structure (VESS). Soil \& Tillage Research, 173, 64-74.

Collins, J.F. \& Brickley, W.D. 1970. Soils of Lyons Estate Celbridge, Co. Kildare, Soil Bulletin No.1. Soil Science Department, University College Dublin, Belfield, Dublin 4, Ireland.

Creamer, R.E., Brennan, F., Fenton, O., Healy, M.G., Lalor, S.T.J., Lanigan, G.J., Regan, J.T. \& Griffiths, B.S. 2010. Implications of the proposed soil framework directive on agricultural systems in Atlantic North-west Europe - a review. Soil Use \& Management., 26, 198-211.

Creamer, R., Simo, I., Reidy, B., Carvalho, J., Fealy, R., Hallett, S., Jone, R., Holden, A., Holden, N., Hannam, J., Massey, P., Mayer, T., McDonald, E., O'Rourke, S., Sills, P., Truckell, I., Zawadzka, J. \& Schulte, R. 2014. Irish soil information synthesis report (2007-S-CD-1-S1). Available at: http://gis.teagasc.ie/soils/ downloads/EPA_RR130_PRINT.pdf; accessed 30/05/2017.

Cui, J. \& Holden, N.M. 2015. The relationship between soil microbial activity and microbial biomass, soil structure and grassland management. Soil \& Tillage Research, 146, 32-38.

Cui, J., Askari, M.S. \& Holden, H.M. 2014. Visual evaluation of soil structure under grassland management. Soil Use and Management, 30, 129-138.

Drewry, J.J. 2006. Natural recovery of soil physical properties from treading damage of pastoral soils in New Zealand and Australia: a review. Agriculture, Ecosystems and Environment, 114, 159-169. 
Emmet-Booth, J.P., Forristal, P.D., Fenton, O., Ball, B.C. \& Holden, N.M. 2016. A review of visual soil evaluation techniques for soil structure. Soil Use and Management, 32, 623-634.

Flint, L.E. \& Flint, A.L. 2002. Porosity. In: Methods of soil analysis part 4, physical methods (eds J.H. Dane \& G.C. Topp), pp. 241254. Soil Science Society of America, Fitchburg, WI.

Giarola, N.F.B., da Silva, A.P., Tormena, C.A., Ball, B.C. \& Rosa, J.A. 2010. Visual soil structure quality assessment on Oxisols under no-tillage system. Scientia Agricola, 64, 479-482.

Guimarães, R.M.L., Ball, B.C. \& Tormena, C.A. 2011. Improvements in the visual evaluation of soil structure. Soil Use and Management, 27, 395-403.

Guimarães, R.M.L., Ball, B.C., Tormena, C.A., Giarola, N.F.B. \& da Silva, A.P. 2013. Relating visual evaluation of soil structure to other physical properties in soils of contrasting texture and management. Soil \& Tillage Research, 127, 92-99.

Guimarães, R.M.L., Neves Junior, A.F., Silva, W.G., Rogers, C.D., Ball, B.C., Montes, C.R. \& Pereira, B.F.F. 2017. The merits of the visual evaluation of soil structure method (VESS) for assessing soil physical quality in the remote, undeveloped regions of the Amazon basin. Soil \& Tillage Research, 173, 75-82.

Herbin, T., Hennessy, D., Richards, K.G., Piwowarczyk, A., Murphy, J.J. \& Holden, N.M. 2011. The effects of dairy cow weight on selected soil physical properties indicative of compaction. Soil Use and Management, 27, 36-44.

Hillel, D. 1998. Environmental soil physics. Academic Press, Cambridge, MA.

Holden, N.M. \& Brereton, A.J. 2004. Definition of agroclimatic regions in Ireland using hydro-thermal and crop yield data. Agriculture \& Forest Meteorology, 122, 175-191.

Houlbrooke, D.J., Paton, R.J., Littlejohn, R.P. \& Morton, J.D. 2011. Land use intensification in New-Zealand: effects on soil properties and pasture production. Journal of Agricultural Science, 149, 337-349.

Kurz, I., O'Reilly, C.D. \& Tunney, H. 2006. Impact of cattle on soil physical properties and nutrient concentrations in overland flow from pastures in Ireland. Agriculture, Ecosystems \& Environment, 113, 378-390.

Met Éireann. 2017. Display and download historic data. Available at: http://www.met.ie/climate-request/; accessed 20/09/2017.

Mueller, L., Shepherd, T.G., Schindler, U., Ball, B.C., Munkholm, L.J., Hennings, V., Smolentseva, E., Rukhovic, O., Lukin, S. \&
$\mathrm{Hu}, \mathrm{C} .2013$. Evaluation of soil structure in the framework of an overall soil quality rating. Soil \& Tillage Research, 127, 74-84.

Munkholm, L.J., Heck, R.J. \& Deen, B. 2013. Long-term rotation and tillage effects on soil structure and crop yield. Soil \& Tillage Research, 127, 85-91.

Newell-Price, J.P., Whittingham, M.J., Chamers, B.J. \& Peel, S. 2013. Visual soil evaluation in relation to measured soil physical properties in a survey of grassland soil compaction in England and Wales. Soil \& Tillage Research, 127, 65-73.

Nie, Z.N., Ward, G.N. \& Michael, A.T. 2001. Impact of pugging by dairy cows on pasture and indicators of pugging damage to pasture soil in soil- western Victoria. Australian Journal of Agricultural Research, 52, 37-43.

Peerlkamp, P. 1959. A visual method of soil structure evaluation. Meded. v.d. Landsbouwhogeschool en Opzoekingsstations van der Staat te Gent. XXIV No. 24, pp. 216-221.

Phelan, P., Keogh, B., Casey, I.A., Necpalova, M. \& Humphreys, J. 2013. The effects of treading by dairy cows on soil properties and herbage production for three white clover-based grazing systems on a clay loam soil. Grass and Forage Science, 68, 548-563.

Piwowarczyk, A., Giuliani, G. \& Holden, N.M. 2011. Can soil moisture deficit be used to forecast when soils are at high risk of drainage owing to grazing animals? Soil Use and Management, 27, 255-263.

Pulido Moncada, M.P., Gabriels, D., Lobo, D., Rey, J.C. \& Cornelis, W.M. 2014. Visual field assessment of soil structural quality in tropical soils. Soil \& Tillage Research, 139, 8-18.

R Core Team. 2014. R: A language and environment for statistical computing. R Foundation for Statistical Computing, Vienna, Austria. Available at: http://www.R-project.org/; accessed 18/07/ 2016.

Roger-Estrade, J., Richard, G., Caneill, J., Boizard, H., Defossez, P. \& Manichon, H. 2004. Morphological characterisation of soil structure in tilled fields: from diagnosis methods to modelling of structural changes over time. Soil \& Tillage Research, 79, 33-49.

Saleh, A. 1994. Measuring and predicting ridge-orientation effect on soil surface roughness. Soil Science Society of America Journal, 58, 1228-1230.

Shepherd, T.G. 2009. Visual soil assessment, Volume 1: Field guide for pastoral grazing and cropping on flat to rolling country, 2nd edn. Horizons regional council, Palmerston North, New Zealand. 